\title{
The Enhanced Monocyte Adhesiveness after UVB Exposure Requires ROS and NF-kB Signaling in Human Keratinocyte
}

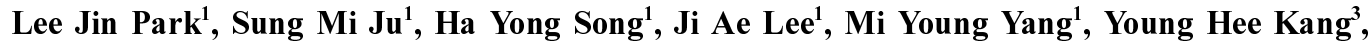 \\ Hyung Joo Kwon ${ }^{4}$, Tae-Yoon Kim ${ }^{5}$, Soo Young Choi ${ }^{1,2, *}$ and Jinseu Park ${ }^{1,2, *}$ \\ ${ }^{1}$ Department of Biomedical Science, Hallym University, Kangwon 200-702, Republic of Korea \\ ${ }^{2}$ Research Institute for Bioscience \& Biotechnology, College of Natural Sciences, Hallym University, \\ Kangwon 200-702, Republic of Korea \\ ${ }^{3}$ Department of Food and Nutrition, College of Medicine, Hallym University, Kangwon 200-702, Republic of Korea \\ ${ }^{4}$ Department of Microbiology, College of Medicine, Hallym University, Kangwon 200-702, Republic of Korea \\ ${ }^{5}$ Research Institutes of Medical Science, The Catholic University of Korea, Seoul 150-010, Republic of Korea
}

Received 9 May 2006, Accepted 8 June 2006

The infiltration of both monocyte and activated $T$ cells in the skin is one of critical steps in the development of UVBinduced inflammation. Upregulation of adhesion molecules such as intercellular adhesion molecule 1 (ICAM-1) on the surface of keratinocytes plays an important role in this process. In this study, we examined the molecular mechanism responsible for UVB-induced expression of ICAM-1 and subsequent monocyte adhesion by keratinocyte. We observed that (1) UVB induced protein and mRNA expression of ICAM-1 in a dose- and time-dependent manner in human keratinocyte cell HaCaT; (2) UVB induced the translocation of NF-kappaB and inhibition of NF-kappaB by NF-kappaB inhibitors suppressed UVBinduced mRNA and protein expression of ICAM-1; (3) UVB increased the intracellular level of reactive oxygen species (ROS) by HaCaT cells; (4) UVB-induced increase of intracellular ROS level was suppressed by pretreatment with diphenyl iodonium (DPI) and $\mathrm{N}$-acetyl cysteine (NAC); and (5) inhibition of UVB-induced ROS production by DPI or NAC suppressed UVB-mediated translocation of NF-kappaB, expression of ICAM-1 and subsequent monocyte adhesion in $\mathrm{HaCaT}$ cells. These results suggest that UVB-induced ROS is involved in the translocation of NF-kappaB which is responsible for expression of ICAM-1 and subsequent increased monocyte adhesion in human keratinocyte.

Keywords: Adhesion, ICAM-1, Inflammation, NF-кB, ROS, UV

\footnotetext{
*To whom correspondence should be addressed.

Tel: 82-33-248-2116; Fax: 82-33-256-3420

E-mail: jinpark@hallym.ac.kr or sychoi@hallym.ac.kr
}

\section{Introduction}

The skin is the primary organ that functions as a physical barrier as well as an active immune organ. The human skin consists of various epidermal and dermal cells including fibroblasts, keratinocytes, melanocytes, Langerhans cells etc. UV radiation in particular UVB $(290-320 \mathrm{~nm})$ from sunlight is one of the major external stimuli that cause inflammatory skin disease, photoaging, cancer (Katiyar et al., 1999). UVB has been shown to exert both antiinflammatory effects and proinflammatory effects on human skin, depending on the context of stimuli or the duration of exposure (Norris et al., 1990; Krutmann and Grewe, 1995). Previous studies demonstrated that UVB inhibited tumor necrosis factor (TNF)- $\alpha$ - or interferon (IFN)- $\gamma$-induced up-regulation of intercellular adhesion molecule-1 (ICAM-1) expression by keratinocyte (Krutmann et al., 1990; Krutmann et al., 1992). UVB selectively upregulates ICAM-1 in human keratinocyte and human dermal microvascular endothelial cells (Norris et al., 1990; Cornelius et al., 1994), indicating a proinflammatory activity of UVB.

UVB-induced infiltration of leukocytes (macrophage/ neutrophils) into the skin is an important step in the development of skin inflammatory diseases. The increased trafficking of leukocytes into the skin has been described in the epidermis as well as the dermis of normal human skin after UVB exposure (Katiyar et al., 1999; Di Nuzzo et al., 2000). Induction of ICAM-1 on the surface of keratinocytes contributes to infiltration of leukocytes into the skin. Increased expression of ICAM-1 on the surface of epidermal keratinocytes as well as dermal microvascular endothelial cells has been proposed as an important regulator in the immunologic skin reactions (Cornelius et al., 1994). The 
epidermal keratinocyte, the major cell type in the skin, can express ICAM-1 in response to cytokines such as TNF- $\alpha$, IL$1 \beta$, and IFN- $\gamma$ as well as UV radiation (Krutmann et al., 1990; Krutmann et al., 1992).

UVB irradiation has been shown to induce a transient increase in the intracellular level of reactive oxygen species (ROS) in keratinocyte as well as ex vivo human skin (Hanson and Clegg, 2002; Baek et al., 2004). Increased levels of ROS within the epidermis and the dermis can induce cellular damage that leads to various skin diseases, including immunomodulation, photoaging and cancers (Katiyar et al., 1999). ROS can also act as second messengers in the intracellular signalling pathways involved in expression of many cellular genes such as matrix metalloproteinases (Schulze-Osthoff et al., 1997; Brenneisen et al., 2002).

While it has been reported that UVB radiation may generate ROS, the possible roles of ROS involved in UVBinduced ICAM-1 expression have not been studied. In the present study, we show that ROS generated by UVB radiation is involved in the induction of ICAM-1 expression and subsequent adhesion of monocyte to keratinocyte through the $\mathrm{NF}-\kappa \mathrm{B}$ dependent pathway.

\section{Materials and Methods}

Cell culture. The immortalized human keratinocyte cell line, $\mathrm{HaCaT}$, was kindly provided by Professor N. Fusenig (German Cancer Research). Cells were maintained in Dulbecco's modified Eagle's medium supplemented with $10 \%(\mathrm{v} / \mathrm{v})$ heat-inactivated fetal bovine serum (FBS), penicillin $\mathrm{G}(100 \mathrm{U} / \mathrm{ml})$, and streptomycin $(100 \mu \mathrm{g} / \mathrm{ml})$ at $37^{\circ} \mathrm{C}$ in a humidified atmosphere containing $5 \%$ $\mathrm{CO}_{2}$ and $95 \%$ air. THP-1 human monocytic cells were maintained in RPMI 1640 medium supplemented with $10 \%(\mathrm{v} / \mathrm{v})$ heatinactivated FBS, penicillin $\mathrm{G}(100 \mathrm{U} / \mathrm{ml})$, streptomycin $(100 \mathrm{~g} / \mathrm{ml})$, and L-glutamine (2 mM) as described previously (Park et al., 2003; Choi et al., 2004).

Reagents. Diphenyl iodonium (DPI), N-acetyl cysteine (NAC) were obtained from Sigma. MG-132 was purchased from Calbiochem. Dichlorodihydrofluorescein diacetate (DCF-DA) and calcein acetoxymethyl ester (calcein-AM) were purchased from Molecular Probe.

UVB irradiation. The HaCaT cells were washed with phosphatebuffered saline (PBS) and exposed to a UVB irradiation system for culture, BIO-SUN with a UV peak at $312 \mathrm{~nm}$ in a thin layer of serum-free DMEM. Control cells were sham-irradiated. After irradiation, the complete media were added and the cells were incubated at $37^{\circ} \mathrm{C}$ in a $5 \% \mathrm{CO}_{2}$ atmosphere for the indicated periods.

Western blot analysis. Cell lysates were prepared from $\mathrm{HaCaT}$ cells as previously described (Kim et al., 2004), and $15 \mu \mathrm{g}$ of total protein was fractionated by electrophoresis on $10 \%$ SDS-polyacrylamide gel. The proteins were then transferred to nitrocellulose membranes and probed with polyclonal rabbit anti-human ICAM-1 (1 : 1000), or polyclonal rabbit anti-human actin $(1: 500)$. The membrane was then incubated with a goat anti-rabbit $\operatorname{IgG}$ antibody $(1: 750)$ conjugated to horseradish peroxidase. Enhanced chemiluminescence (ECL; Amesham) was used to detect bound antibody

RT-PCR analysis. Total RNA was isolated from HaCaT cells using a Trizol reagent kit (Gibco BRL) according to the manufacturer's instructions. Five micrograms of total RNA was reverse-transcribed with $10,000 \mathrm{U}$ of reverse transcriptase and 0.5 $\mathrm{g} / \mathrm{L}$ oligo-(dT)15 primer (Bioneer). One microliter of the cDNA synthesis was subjected to the standard PCR for 38 cycles by using primers as: human ICAM-1, 5'-GGTGACGCTGAATGGGGTTCC3' (sense) and 5'-GTCCTCATGGTGGGGCTATGACTC-3' (antisense) (907 bp); and human $\beta$-actin, 5'-GACTACCTCATGAAGATC-3' (sense) and 5'-GATCCACATCTGCTGGAA-3 (antisense) (228 bp) (Choi et al., 2004). PCR products were resolved on a $1 \%$ agarose gel and visualized with UV light after ethidium bromide.

Measurement of intracellular ROS levels. For analysis of intracellular ROS levels, the oxidation-sensitive fluorescent probe, DCF-DA was used as described previously (Gottlieb et al., 2000; Park et al., 2004). To measure the levels of ROS production, $\mathrm{HaCaT}$ cells were exposed to UVB irradiation and incubated for varying time periods (0-60 min). To examine the effect of NAC and DPI on UVB-induced ROS production, HaCaT cells were incubated in the absence or presence of these inhibitors for $1 \mathrm{~h}$, and then exposed to UVB irradiation. Cells were washed twice with Hank's balanced salt solution (HBSS) and incubated with DCF-DA (2.5 $\mathrm{mM}$ ) for $10 \mathrm{~min}$. The cellular fluorescent images were obtained using a Zeiss Axiovert S100 microscope with a confocal laserscanning system (Bio-Rad MRC-1024ES) by using laser excitation at $494 \mathrm{~nm}$ as previously described (Park et al., 2004).

NF- $\kappa$ B protein localization. The NF- $\kappa B$ p 65 nuclear localization was detected by indirect immunofluorescence assay using confocal microscopy as described previously (Kim et al., 2003). HaCaT cells grown on a glass slide in a six-well plate were exposed to UVB and incubated for the indicated time periods. $\mathrm{HaCaT}$ cells were washed with PBS and then were fixed with $4 \%$ ice-cold formaldehyde for 30 min. Polyclonal antibody to human NF-kB p65 (1:50) was applied for $1 \mathrm{~h}$ followed by $1 \mathrm{~h}$ incubation with fluorescein isothiocyanate-conjugated goat anti-rabbit $\operatorname{IgG}(1: 200)$. The cells were transferred to a chamber on the stage of a Zeiss Axiovert S100 microscope and observed with a confocal laser-scanning system (Bio-Rad MRC-1024ES). The fluorescence images (excitation 494 $\mathrm{nm} / \mathrm{emission} 518 \mathrm{~nm}$ ) of the cells were recorded every $0.25 \mathrm{~s}$ $(\times 640)$.

Cell adhesion assay. Adherence of THP-1 cells to HaCaT cells was assayed using a cell-cell adhesion assay as described elsewhere (Choi et al., 2004). Briefly, HaCaT cells were cultured at a density of $6.0 \times 10^{4}$ cells on a 4-well glass chamber slide containing 25 mmol/L HEPES-buffered M199 with 10\% FBS. HaCaT cells were pretreated with inhibitors for the indicated time periods. After pretreatment, HaCaT cells were exposed to UVB irradiation. $\mathrm{HaCaT}$ cells were washed three times with PBS before cell-cell adhesion assay. THP-1 cells were labeled for $30 \mathrm{~min}$ with $5 \mu \mathrm{mol} / \mathrm{L}$ calcein-AM (Molecular Probes, Inc.). The labeled THP-1 (5.0 $\times$ 
$10^{5}$ ) was cocultured with $\mathrm{HaCaT}$ cells for $1 \mathrm{~h}$. Cocultured cells were washed three times with PBS. The fluorescence images were obtained at $485 \mathrm{~nm}$ excitation and $538 \mathrm{~nm}$ emission using a SPOT II digital camera-attached fluorescence microscope with Spot II data acquisition software (Diagnostic Instrument). For the adhesion quantification, the calcein-AM fluorescent intensity was measured at $485 \mathrm{~nm}$ excitation and $538 \mathrm{~nm}$ emission by a Fluoroskan ELISA plate reader (Labsystems Oy).

\section{Results}

Induction of ICAM-1 expression by UVB in human keratinocyte cells. It was previously demonstrated that UVB induces expression of ICAM-1 by human keratinocyte (Krutmann and Grewe, 1995). To understand the molecular mechanisms occurring in UVB-induced ICAM-1 expression, we examined the effects of UVB irradiation upon ICAM-1 expression in the human keratinocyte cell line HaCaT. HaCaT cells were exposed to varying doses of UVB $\left(0-100 \mathrm{~mJ} / \mathrm{cm}^{2}\right)$ and analyzed for expression of ICAM-1 protein after $20 \mathrm{~h}$ later. Maximal induction of ICAM-1 was observed at the dose of $40 \mathrm{~mJ} / \mathrm{cm}^{2}$ (Fig. 1A). Analysis of the kinetics of protein expression indicated that $20 \mathrm{~h}$ incubation after UVB exposure was optimal (Fig. 1B).

Next, we analyzed the induction of ICAM-1 mRNA expression in HaCaT cells after treatment with UVB (Fig. 1C). Cells were exposed with different UVB doses (0-100 mJ/ $\mathrm{cm}^{2}$ ) and at $10 \mathrm{~h}$ later ICAM-1 mRNA was measured by RTPCR. Optimal induction of ICAM-1 mRNA was observed at the dose of $40 \mathrm{~mJ} / \mathrm{cm}^{2}$ (Fig. 1C). As shown in Fig. 1D, a timedependent increase in levels of ICAM-1 mRNA was observed in $\mathrm{HaCaT}$ cells after UVB $\left(40 \mathrm{~mJ} / \mathrm{cm}^{2}\right)$ irradiation.
$\mathrm{NF}-\kappa \mathrm{B}$ is responsible for induction of ICAM-1 expression by UVB in human keratinocyte cells. Since $\mathrm{NF}-\kappa \mathrm{B}$ is a pivotal transcription factor of gene expression involved in photobiology (Legrand-Poels et al., 1998) and ROS has been known to be a key regulator in NF- $\mathrm{BB}$ activation (Sen and Packer, 1996; Legrand-Poels et al., 1998), we examined whether UVB can induce activation of NF- $\kappa \mathrm{B}$ in $\mathrm{HaCaT}$ cells. HaCaT cells were exposed to UVB $\left(40 \mathrm{~mJ} / \mathrm{cm}^{2}\right)$ for various time periods, the translocation of NF- $\kappa \mathrm{B}$ was analyzed by indirect immunofluorescence. Nuclear accumulation of $\mathrm{NF}-\kappa \mathrm{B}$ p65 in $\mathrm{HaCaT}$ cells were strongly induced $60 \mathrm{~min}$ after exposure to UVB (40 mJ/cm²) (Fig. 2). Next, we investigated whether UVB-induced translocation of $\mathrm{NF}-\kappa \mathrm{B}$ is necessary for inducing ICAM-1 expression in HaCaT cells. To address this, we used various pharmacological NF- $\kappa \mathrm{B}$ inhibitors, MG132, TLCK, and Bay 11-7082. HaCaT cells were incubated in the absence or presence of these inhibitors for $1 \mathrm{~h}$, exposed to UVB $\left(40 \mathrm{~mJ} / \mathrm{cm}^{2}\right)$, and then expression of ICAM-1 was assessed by RT-PCR and Western blot analysis. As shown in Fig 3, pretreatment with MG-132, TLCK, or Bay 11-7082 suppressed UVB-induced expression of ICAM-1 mRNA (Fig. $3 \mathrm{~A}$ ) and protein (Fig. 3B). These results indicate that NF- $\kappa \mathrm{B}$ activation is required for UVB-induced expression of ICAM1 by HaCaT cells.

Generation of ROS by UVB in keratinocyte cells. Since ROS were generated in keratinocyte as well as ex vivo human skin after UVB irradiation (Hanson and Clegg, 2002; Baek et al., 2004), ROS may be involved in UVB-induced increase of ICAM-1 expression by human keratinocyte cells. We examined whether ROS can be generated after UVB irradiation in HaCaT cells. After exposure to UVB $\left(40 \mathrm{~mJ} / \mathrm{cm}^{2}\right)$ for various time

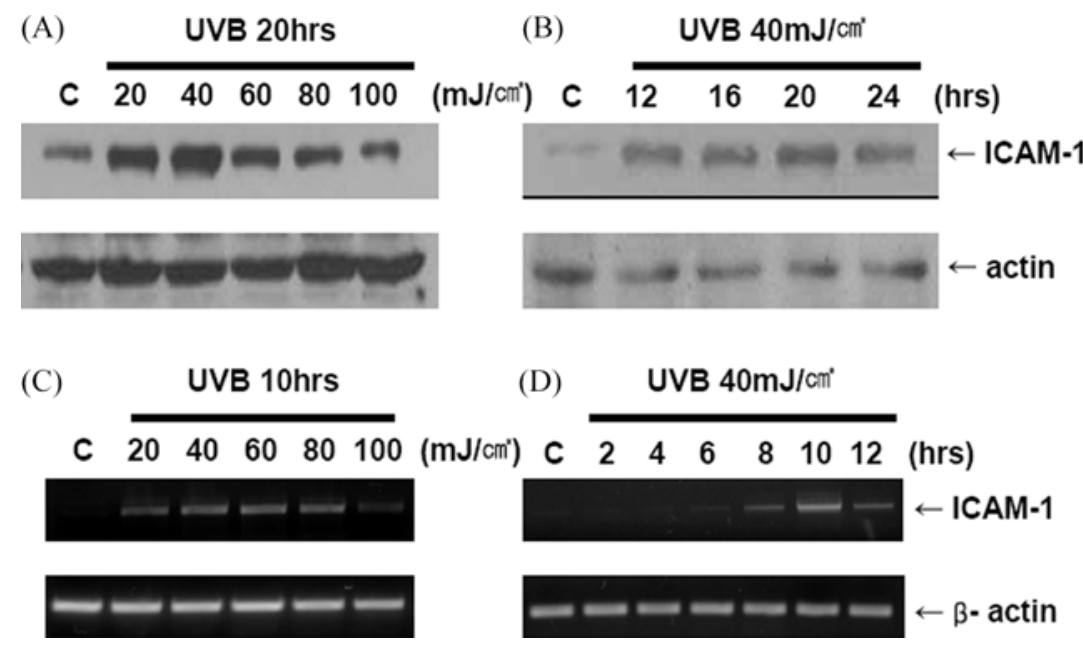

Fig. 1. UVB induces expression of ICAM-1 by human keratinocytes. A: HaCaT cells were exposed to varying dose of UVB (0-100 $\left.\mathrm{mJ} / \mathrm{cm}^{2}\right)$, and then analyzed for ICAM-1 expression by Western blot analysis. B: Cells were exposed to UVB $\left(40 \mathrm{~mJ} / \mathrm{cm}^{2}\right)$ for varying times, and then were examined for ICAM-1 expression. C: HaCaT cells were exposed to varying dose of UVB $\left(0-100 \mathrm{~mJ} / \mathrm{cm}^{2}\right)$, and then analyzed for ICAM-1 mRNA expression by RT-PCR. D: Cells were exposed to UVB $\left(40 \mathrm{~mJ} / \mathrm{cm}^{2}\right)$ for varying times, and then were examined for ICAM-1 mRNA expression. 


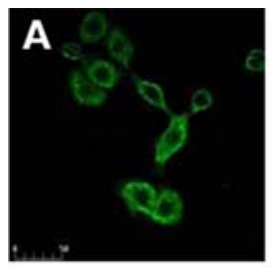

control

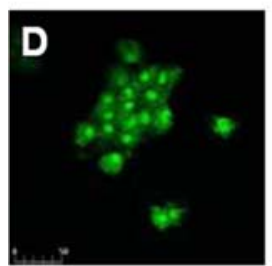

UVB $40 \mathrm{~mJ} / \mathrm{cm}^{2}$, $60 \mathrm{~min}$

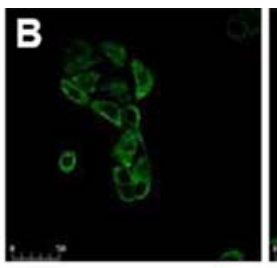

UVB $40 \mathrm{~mJ} / \mathrm{cm}^{\prime}$, $15 \mathrm{~min}$

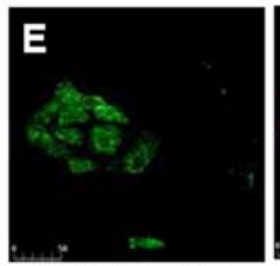

UVB $40 \mathrm{~mJ} / \mathrm{cm}^{\prime}$, $180 \mathrm{~min}$

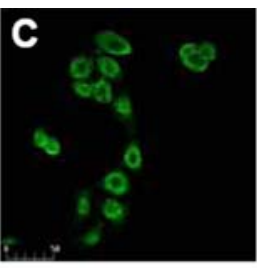

UVB $40 \mathrm{~mJ} / \mathrm{cm}^{2}$, $30 \mathrm{~min}$

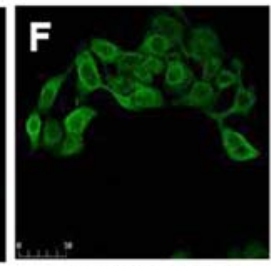

UVB $40 \mathrm{~mJ} / \mathrm{cm}^{2}$, $60 \mathrm{~min}+$ TLCK $50 \mu \mathrm{M}$

Fig. 2. NF- $\kappa B$ nuclear translocation in HaCaT exposed to UVB. The NF- $\mathrm{KB}$ localization in HaCaT cells exposed to UVB (40 $\mathrm{mJ} / \mathrm{cm}^{2}$ ) was visualized with a confocal microscopy by indirect immunofluorescence using anti-NF- $\kappa$ B p65 antibody. TNF- $\alpha$ (20 $\mathrm{ng} / \mathrm{ml}$ for $20 \mathrm{~min}$ ) was used as positive control. To analyze the effect of NF- $\kappa B$ inhibitor on UVB-induced NF- $\kappa B$ localization, $\mathrm{HaCaT}$ cells pre-treated with TLCK for $1 \mathrm{~h}$ were exposed to UVB and then the NF- $\mathrm{KB}$ p 65 localization was examined.

periods (0-60 min), cells were stained with DCF-DA, which has been used as a general marker of intracellular ROS production

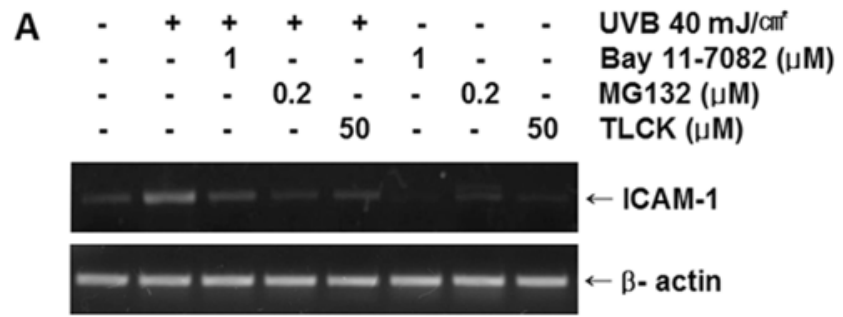

B

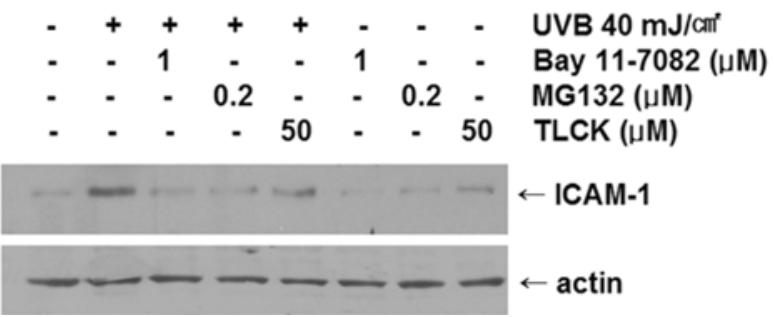

Fig. 3. NF- $\mathrm{kB}$ inhibitors suppress UVB-induced ICAM-1 expression. HaCaT cells were incubated with MG-132, Bay 117082 and TLCK for $1 \mathrm{~h}$, exposed to UVB $\left(40 \mathrm{~mJ} / \mathrm{cm}^{2}\right)$, and then ICAM-1 expression were measured by RT-PCR (A) and Western blot assay (B).

(Park et al., 2004). As shown in Fig. 4, ROS levels increased in time-dependent manner in $\mathrm{HaCaT}$ cells as early as 5 min after UVB exposure and were maintained up to $1 \mathrm{~h}$ after treatment. To further characterize ROS production by UVB irradiation, we utilized an antioxidant, NAC, and a flavoprotein inhibitor, DPI. DPI has been used widely to inhibit NADPH oxidase activity in

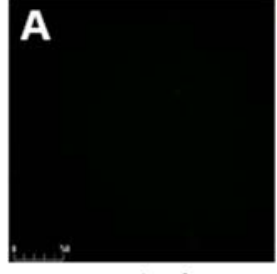

control

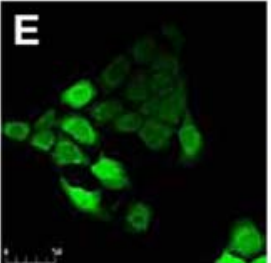

UVB $40 \mathrm{~mJ} / \mathrm{cm}^{\prime}$, $30 \mathrm{~min}$

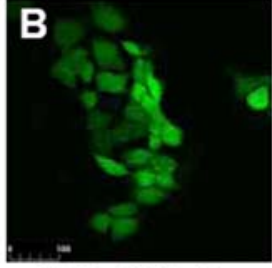

$\mathrm{H}_{2} \mathrm{O}_{2} 100 \mu \mathrm{M}$, $15 \mathrm{~min}$

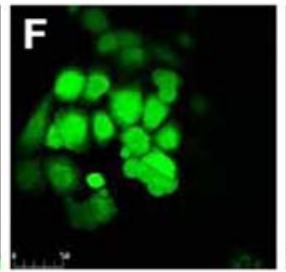

UVB $40 \mathrm{~mJ} / \mathrm{cm}^{\prime}$, $1 \mathrm{hr}$

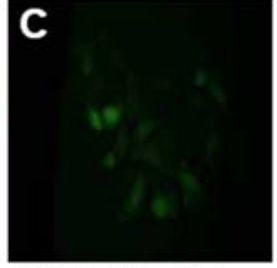

UVB $40 \mathrm{~mJ} / \mathrm{cm}^{\prime}$, $5 \mathrm{~min}$

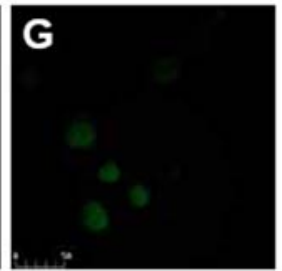

UVB $40 \mathrm{~mJ} / \mathrm{cm}^{\circ}$, $1 \mathrm{hr}+\mathrm{DPI} 10 \mu \mathrm{M} \quad 1 \mathrm{hr}+\mathrm{NAC} 20 \mathrm{mM}$

Fig. 4. Analysis of ROS production in the HaCaT cells exposed to UVB. HaCaT cells exposed to UVB $\left(40 \mathrm{~mJ} / \mathrm{cm}^{2}\right) \mathrm{were}$ incubated for various time periods $(0-1 \mathrm{~h})$, and intracellular ROS levels were measured after staining with dichlorodihydrofluorescein diacetate (DCF-DA). Visualization of the ROS of the treated cells was measured by confocal microscopy (original magnification, X 200). Cells treated with $\mathrm{H}_{2} \mathrm{O}_{2}(100 \mu \mathrm{M})$ for 15 min were analyzed for intracellular ROS levels as positive controls. To analyze the effect of diphenyl iodonium (DPI) and N-acetyl cysteine (NAC) on UVB-induced ROS production, HaCaT cells were incubated in the absence or presence of NAC $(20 \mathrm{mM})$ or DPI $(10 \mu \mathrm{M})$ for $1 \mathrm{~h}$, exposed to UVB $\left(40 \mathrm{~mJ} / \mathrm{cm}^{2}\right)$, and incubated for an additional $1 \mathrm{~h}$ and then intracellular ROS were measured. 


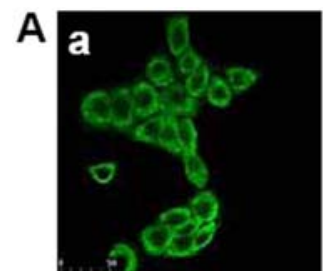

control

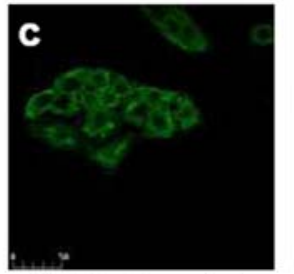

UVB $40 \mathrm{~mJ} / \mathrm{cm}^{\prime}$

$+\mathrm{DPI} 10 \mu \mathrm{M}$

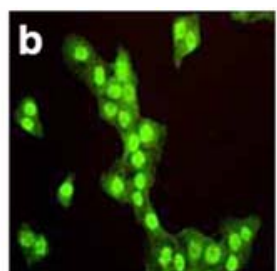

UVB $40 \mathrm{~mJ} / \mathrm{cm}^{\prime}$,

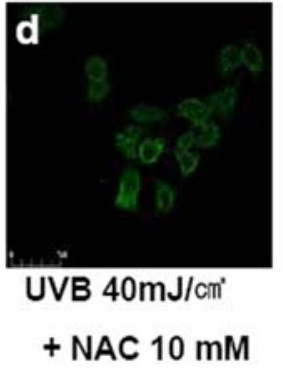

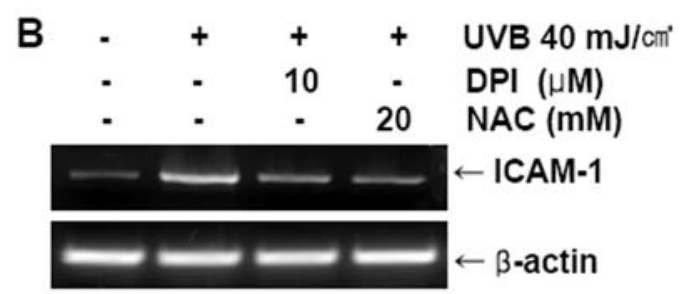

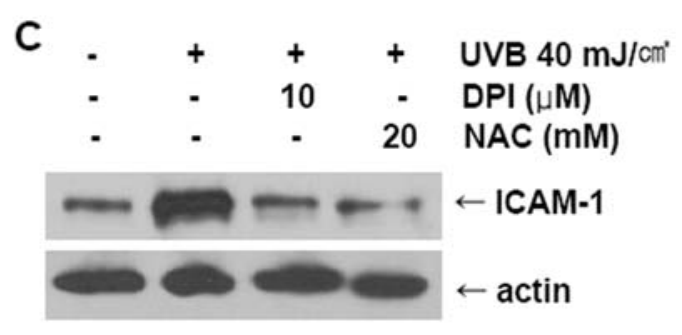

Fig. 5. Effects of diphenyl iodonium (DPI) and N-acetyl cysteine (NAC) on UVB-induced NF- $\mathrm{KB}$ nuclear translocation and ICAM-1 expression in HaCaT exposed to UVB. A. To analyse the effect of diphenyl iodonium (DPI) and N-acetyl cysteine (NAC) on UVBinduced NF- $\mathrm{KB}$ localization, HaCaT cells pre-treated with NAC or DPI for $1 \mathrm{~h}$ were exposed to UVB and then the NF- $\mathrm{KB}$ p65 localization was examined. B and C: HaCaT cells pre-treated with DPI $(10 \mu \mathrm{M})$ or NAC $(20 \mathrm{mM})$ for $1 \mathrm{~h}$ were exposed to UVB (40 $\mathrm{mJ} / \mathrm{cm}^{2}$ ), incubated for an additional $20 \mathrm{~h}$, and then ICAM-1 mRNA (B) and protein (C) expression were examined.

non-phagocytic cells (Cross and Jones, 1986; Doussiere and Vignais, 1992). Cells were incubated in the absence or presence of these inhibitors for $1 \mathrm{~h}$, exposed to UVB $\left(40 \mathrm{~mJ} / \mathrm{cm}^{2}\right)$ for $1 \mathrm{~h}$, and then intracellular ROS was measured after staining with DCF-DA. As shown in Fig. 4, pretreatment with DPI and NAC suppressed UVB-induced increase of intracellular ROS levels in HaCaT cells. These results indicate that UVB irradiation induces production of ROS in a time-dependent manner in HaCaT cells.

ROS are responsible for UVB-induced activation of NF$\kappa \mathbf{B}$ and ICAM-1 expression. Next, we used DPI and NAC to investigate the role of ROS on UVB-induced translocation of $\mathrm{NF}-\kappa \mathrm{B}$. HaCaT cells were incubated in the absence or presence of these inhibitors for $1 \mathrm{~h}$, exposed to UVB (40 mJ/ $\mathrm{cm}^{2}$ ), and $1 \mathrm{~h}$ later the translocation of NF- $\mathrm{BB}$ were analyzed by fluorescence microscopy. As shown in Fig. 5A, pretreatment with DPI suppressed UVB-induced translocation of NF- $\kappa B$. UVB-induced translocation of NF- $\kappa \mathrm{B}$ was also inhibited by pretreatment with NAC. We further used these inhibitors to investigate the role of ROS on UVB-induced increase of ICAM-1 expression in keratinocytes. Cells were incubated in the absence or presence of DPI or NAC for $1 \mathrm{~h}$, exposed to UVB $\left(40 \mathrm{~mJ} / \mathrm{cm}^{2}\right)$, and then ICAM-1 expression were analyzed by Western blot analysis. Pretreatment with DPI or NAC suppressed significantly ICAM-1 mRNA (Fig. 5B) and protein (Fig. 5C) expression.

ROS are responsible for UVB-induced monocyte adhesion to keratinocytes. Next, we examined the effect of DPI and
NAC on monocyte adhesion to keratinocytes. HaCaT cells were incubated in the absence or presence of DPI or NAC for $1 \mathrm{~h}$, exposed to UVB $\left(40 \mathrm{~mJ} / \mathrm{cm}^{2}\right)$, and then analyzed for monocyte adhesion to keratinocytes. As shown in Fig. 6, significant adhesion of monocytes was observed following UVB exposure of HaCaT cells, as compared with untreated conditions. Adhesion between THP-1 and HaCaT cells was markedly attenuated in UVB-exposed cells pre-treated with NAC or DPI (Fig. 6B).

\section{Discussion}

One of characteristic features of skin inflammatory disease is the infiltration of leukocytes in the epidermis as well as dermis of the skin. In UVB-induced skin inflammation, adhesion of activated leukocytes to dermal microvascular endothelial cells is considered to be a prerequisite for the development of immune response in the skin. Once within the skin, these leukocytes may activate keratinocyte and fibroblast directly and/or via the production of proinflammatory cytokines, such as TNF and gamma interferon (Mitra et al., 1993). Therefore, expression of adhesion molecules such as ICAM-1 by skin cells including keratinocyte may be an important step in the induction of inflammatory skin diseases. The molecular mechanism by which UVB induces ICAM-1 expression of keratinocyte has not been fully understood. We demonstrate that ROS generated by UVB mediates activation of NF-кB, up-regulation of ICAM-1 and subsequent increased monocyte adhesion in human keratinocyte, HaCaT. 


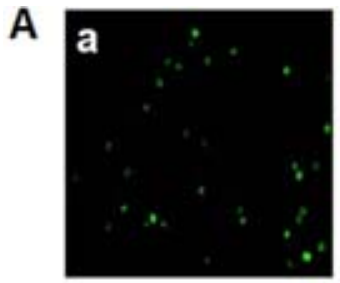

Control

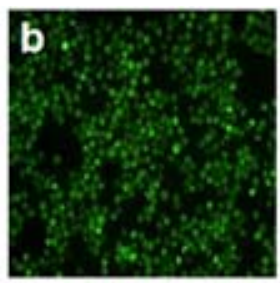

UVB $40 \mathrm{~mJ} / \mathrm{call}$

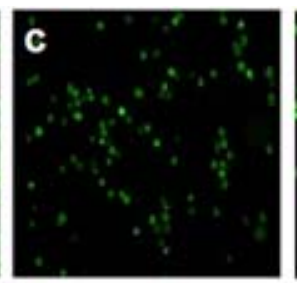

UVB $40 \mathrm{~mJ} / \mathrm{cm}$ +NAC $20 \mathrm{mM}$

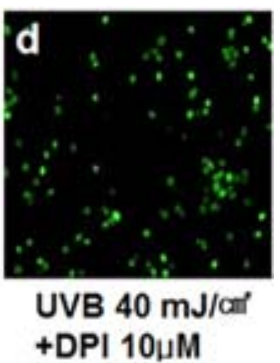

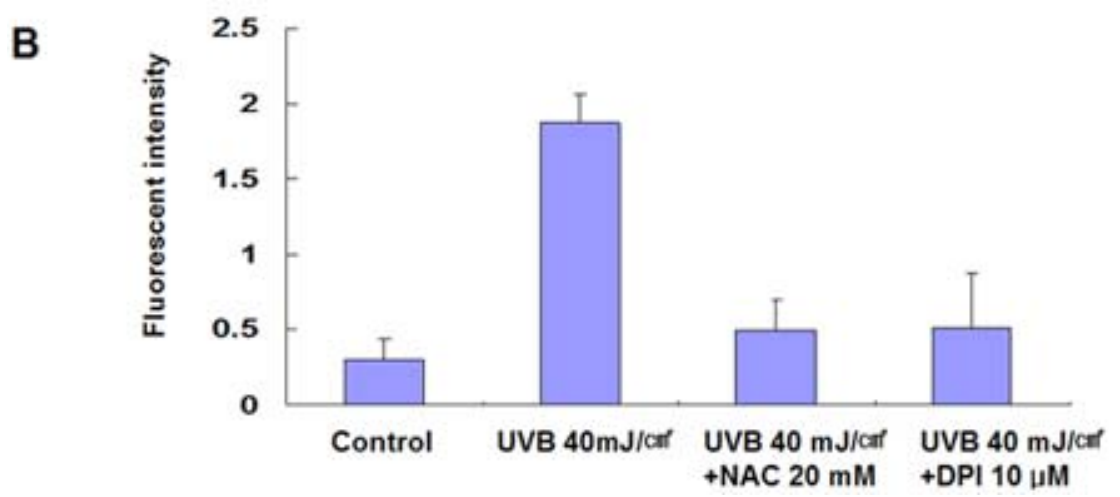

Fig. 6. Effects of diphenyl iodonium (DPI) and N-acetyl cysteine (NAC) on monocyte adhesion to keratinocytes. A: HaCaT cells pretreated with NAC or DPI for $1 \mathrm{~h}$ were exposed to UVB $\left(40 \mathrm{~mJ} / \mathrm{cm}^{2}\right)$ and incubated for $20 \mathrm{~h}$. UVB-exposed HaCaT cells were cocultured with calcein-AM-labeled THP-1 monocytes. Microphotographs were obtained using fluorescence microscopy (original magnification, $\times 100)$. B: HaCaT cells pre-treated with NAC or DPI for $1 \mathrm{~h}$ were exposed to UVB $\left(40 \mathrm{~mJ} / \mathrm{cm}^{2}\right)$, and cocultured with calcein-AM-labeled THP-1. The calcein-AM fluorescent intensity was measured by an ELISA plate reader. Values are means $\pm \mathrm{SEM}$, $\mathrm{n}=4$.

Our results are consistent with previous report that UVB exerts pro-inflammatory effects on human skin (Krutmann and Grewe, 1995; Norris et al., 1999). Previous results have shown that UVB can exert both antiinflammatory effects and proinflammatory effects depending on the duration of irradiation (Norris et al., 1999). They have demonstrated that UVB $\left(100 \mathrm{~mJ} / \mathrm{cm}^{2}\right)$ significantly inhibited enhanced expression of ICAM-1 on the surface of cultured human keratinocytes by gamma interferon $24 \mathrm{~h}$ after irradiation. However, ICAM-1 expression was greatly induced at 48,72 , and $96 \mathrm{~h}$ after UVB irradiation $\left(10\right.$ to $\left.100 \mathrm{~mJ} / \mathrm{cm}^{2}\right)$ alone. They suggested that the late induction of ICAM-1 by UVB might be an important step in the induction of UVB-induced skin inflammation. Upregulation of ICAM-1 mRNA was detected $6 \mathrm{~h}$ after UVB irradiation, and increase of ICAM-1 protein expression in the irradiated $\mathrm{HaCaT}$ cells was observed at $12 \mathrm{~h}$ after irradiation with a peak at $20 \mathrm{~h}$. This early induction pattern of ICAM-1 protein expression after UVB irradiation is different from the results obtained from cultured human keratinocytes. This might be due to the different properties between the cell line and the primary cells.

ICAM-1 is constitutively expressed at low levels in keratinocyte. However, its expression is greatly enhanced by a variety of stimuli such as cytokines (interferon- $\gamma, \mathrm{TNF}-\alpha$ ) and UV radiation (Mitra et al., 1993; Norris et al., 1999). Enhanced expression of adhesion molecules such as ICAM-1 on the surface of keratinocyte is required for keratinocyteleukocyte interaction. The increased infiltration of leukocytes into the skin has been observed in the epidermis of normal human skin after UVB exposure (Katiyar et al., 1999). Our results showed that UVB-induced increase in ICAM-1 expression is regulated at the transcriptional level in an NF$\kappa \mathrm{B}$-dependent pathway. Although ICAM-1 expression is regulated in the NF- $\kappa \mathrm{B}$ dependent manner in response to UVB, signaling pathways involved in expression of this gene remain unknown. Our results showed that increase of ICAM1 expression on the keratinocyte exposed to UV is mediated by ROS. UVB-induced generation of ROS was inhibited by DPI, suggesting that a NADPH oxidase is involved in the generation of ROS by UVB radiation. This result is consistent with previous studies demonstrating that the plasma membranebound NADPH oxidase is a major source of ROS production induced by UVB in keratinocytes (Beak et al., 2004; Wang and Kochevar, 2005). However, DPI is not specific for NADPH oxidase. DPI can inhibit a variety of flavoprotein oxidoreductases such as NADPH oxidase, nitric oxide synthase, xanthine oxidase, $\mathrm{P}-450$ reductase, and mitochondrial respiratory chain complex I NADPH-ubiquinone oxidoreductase (Cross and Jones, 1986; Stuehr et al., 1991; Doussiere and Vignais, 1992; Li and Trush, 1998). Even though our results suggest that a NADPH oxidase may play a role in UVB-induced ROS production, further study is required to define the exact source 
of ROS. Since keratinocytes express NOX1, a homologue of gp91phox which is one of NADPH oxidase components (Chamulitrat et al., 2004), it would be helpful to use a specific inhibitor of NADPH oxidase such as tat-gp91 which has been shown to inhibit p47(phox) association with gp91(phox) in $\mathrm{NAD}(\mathrm{P}) \mathrm{H}$ oxidase (Rey et al., 2001).

UVB-induced NF- $\mathrm{KB}$ activation was significantly inhibited in cells exposed to UVB in the presence of NAC or DPI. In addition, both NAC and DPI inhibited ROS-mediated enhancement of expression of ICAM-1 and subsequent increased adhesion of monocyte to keratinocyte. These results indicate that ROS is involved in the signal transduction pathway leading to nuclear translocation of NF- $\mathrm{kB}$ and to NF$\kappa \mathrm{B}-$ activated ICAM-1 expression in $\mathrm{HaCaT}$ cells. Elucidation of the central role of ROS in the inducible expression of ICAM-1 and the subsequent increased adhesion of monocyte to keratinocyte may lead to the development of effective therapeutic agents for skin inflammation induced by UVB. Currently available agents, such as corticosteroids, antihistamines, or immunosuppressants, have been considered to have a beneficial effect against skin inflammatory diseases (Hengge et al., 2006, Massey and Lichtenstein, 1990, Tomi and Luger, 2003). However, the adverse effects of these agents resulted in limitation to treat skin inflammation. The observed inhibition of ICAM expression and subsequent increased adhesion of monocyte to $\mathrm{HaCaT}$ by the antioxidants suggested that the natural compounds with antioxidant activity may be useful as therapeutic agents for UVB-induced ROS-associated inflammatory skin diseases.

Acknowledgments This work was supported in part by a Next Generation Growth Engine Program Grant from the Korean Science and Engineering Foundation, and in part by a Regional Innovation Center Grant from the Korean Ministry of Commerce, Industry and Energy.

\section{References}

Beak, S. M., Lee, Y. S. and Kim, J. A. (2004) NADPH oxidase and cyclooxygenase mediate the ultraviolet B-induced generation of reactive oxygen species and activation of nuclear factor-kappaB in HaCaT human keratinocytes. Biochimie. 86, 425-429.

Brenneisen, P., Sies, H. and Scharffetter-Kochanek, K. (2002) Ultraviolet-B irradiation and matrix metalloproteinases: from induction via signaling to initial events. Ann. N. Y. Acad. Sci. 973, 31-43.

Chamulitrat, W., Stremmel, W., Kawahara, T., Rokutan, K., Fujii, H., Wingler, K., Schmidt, H. H. and Schmidt, R. (2004) A constitutive NADPH oxidase-like system containing gp91phox homologs in human keratinocytes, J. Invest. Dermatol. 122, 1000-1009.

Choi, J. S., Choi, Y. J., Park, S. H., Kang, J. S. and Kang, Y. H. (2004) Flavones mitigate tumor necrosis factor-alpha-induced adhesion molecule upregulation in cultured human endothelial cells: role of nuclear factor-kappa B. J. Nutr. 134, 1013-1019.
Cornelius, L. A., Sepp, N., Li, L. J., Degitz, K., Swerlick, R. A., Lawley, T. J. and Caughman, S. W. (1994) Selective upregulation of intercellular adhesion molecule (ICAM-1) by ultraviolet $\mathrm{B}$ in human dermal microvascular endothelial cells. J. Invest. Dermatol. 103, 23-28.

Cross, A. R. and Jones, O. T. (1986) The effect of the inhibitor diphenylene iodonium on the superoxide-generating system of neutrophils. Specific labelling of a component polypeptide of the oxidase. Biochem. J. 237, 111-116.

Doussiere, J. and Vignais, P. V. (1992) Diphenylene iodonium as an inhibitor of the NADPH oxidase complex of bovine neutrophils. Factors controlling the inhibitory potency of diphenylene iodonium in a cell-free system of oxidase activation. Eur. J. Biochem. 208, 61-71.

Gottlieb, E., Vander Heiden, M. G. and Thompson, C. B. (2000) $\mathrm{Bcl}-\mathrm{xL}$ prevents the initial decrease in mitochondrial membrane potential and subsequent reactive oxygen species production during tumor necrosis factor alpha-induced apoptosis. Mol. Cell. Biol. 20, 5680-5689.

Hanson, K. M. and Clegg, R. M. (2002) Observation and quantification of ultraviolet-induced reactive oxygen species in ex vivo human skin. Photochem. Photobiol. 76, 57-63.

Hengge, U. R., Ruzicka, T., Schwartz, R. A. and Cork, M. J. (2006) Adverse effects of topical glucocorticosteroids. J. Am. Acad. Dermatol. 54, 1-15.

Katiyar, S. K., Matsui, M. S., Elmets, C. A. and Mukhtar, H. (1999) Polyphenolic antioxidant (-)-epigallocatechin-3-gallate from green tea reduces UVB-induced inflammatory responses and infiltration of leukocytes in human skin. Photochem. Photobiol. 69, 148-153.

Kim, D. S., Han, J. H. and Kwon, H. J. (2003) NF-kappaB and cJun-dependent regulation of macrophage inflammatory protein2 gene expression in response to lipopolysaccharide in RAW 264.7 cells. Mol. Immunol. 40, 633-643.

Kim, J. S., Ryu, J., Hwang, S. B., Lee, S. Y., Choi, S. Y. and Park, J. (2004) Suppression of ceramide-induced cell death by hepatitis C virus core protein. J. Biochem. Mol. Biol. 37, 192198.

Krutmann, J., Kock, A., Schauer, E., Parlow, F., Moller, A., Kapp, A., Forster, E., Schopf, E. and Luger, T. A. (1990) Tumor necrosis factor beta and ultraviolet radiation are potent regulators of human keratinocyte ICAM-1 expression. J. Invest. Dermatol. 95, 127-131.

Krutmann, J., Czech, W., Parlow, F., Trefzer, U., Kapp, A., Schopf, E. and Luger, T. A. (1992) Ultraviolet radiation effects on human keratinocyte ICAM-1 expression: UV-induced inhibition of cytokine-induced ICAM-1 mRNA expression is transient, differentially restored for IFN gamma versus TNF alpha, and followed by ICAM-1 induction via a TNF alphalike pathway. J. Invest. Dermatol. 98, 923-928.

Krutmann, J. and Grewe, M. (1995) Involvement of cytokines, DNA damage, and reactive oxygen intermediates in ultraviolet radiation-induced modulation of intercellular adhesion molecule-1 expression. J. Invest. Dermatol. 105, 67-70.

Legrand-Poels, S., Schoonbroodt, S., Matroule, J. Y. and Piette, J. (1998) Nf-kappa B: an important transcription factor in photobiology. J. Photochem. Photobiol. B. 45, 1-8.

Li, Y. and Trush, M. A. (1998) Diphenyleneiodonium, an $\mathrm{NAD}(\mathrm{P}) \mathrm{H}$ oxidase inhibitor, also potently inhibits mitochondrial reactive oxygen species production. Biochem. 
Biophys. Res. Commun. 253, 295-299.

Massey, W. A. and Lichtenstein, L. M. (1990) The effects of antihistamines beyond $\mathrm{H} 1$ antagonism in allergic inflammation. J. Allergy Clin. Immunol. 86, 1019-1024.

Mitra, R. S., Shimizu, Y. and Nickoloff, B. J. (1993) Histamine and cis-urocanic acid augment tumor necrosis factor-alpha mediated induction of keratinocyte intercellular adhesion molecule-1 expression. J. Cell. Physiol. 156, 348-357.

Norris, D. A., Lyons, M. B., Middleton, M. H., Yohn, J. J. and Kashihara-Sawami, M. (1990) Ultraviolet radiation can either suppress or induce expression of intercellular adhesion molecule 1 (ICAM-1) on the surface of cultured human keratinocytes. J. Invest. Dermatol. 95, 132-138.

Di Nuzzo, S., Sylva-Steenland, R. M., Koomen, C. W., de Rie, M. A., Das, P. K., Bos, J. D. and Teunissen, M. B. (2000) Exposure to UVB induces accumulation of LFA-1+ T cells and enhanced expression of the chemokine psoriasin in normal human skin. Photochem. Photobiol. 72, 374-382.

Park, J., Choi, K., Jeong, E., Kwon, D., Benveniste, E. N. and Choi, C. (2004) Reactive oxygen species mediate chloroquineinduced expression of chemokines by human astroglial cells. Glia 47, 9-20.

Park, J., Kwon, D., Choi, C., Oh, J. W. and Benveniste, E. N.
(2003) Chloroquine induces activation of nuclear factor-kappaB and subsequent expression of pro-inflammatory cytokines by human astroglial cells. J. Neurochem. 84, 1266-1274.

Rey, F. E., Cifuentes, M. E., Kiarash, A., Quinn, M. T. and Pagano, P. J. (2001) Novel competitive inhibitor of NAD(P)H oxidase assembly attenuates vascular $\mathrm{O}(2)(-)$ and systolic blood pressure in mice. Circ. Res. 89, 408-414.

Sen, C. K. and Packer, L. (1996) Antioxidant and redox regulation of gene transcription. FASEB J. 10, 709-720.

Schulze-Osthoff, K., Bauer, M. K., Vogt, M. and Wesselborg, S. (1997) Oxidative stress and signal transduction. Int. J. Vitam. Nutr. Res. 67, 336-342.

Stuehr, D. J., Fasehun, O. A., Kwon, N. S., Gross, S. S., Gonzalez, J. A., Levi, R. and Nathan, C. F. (1991) Inhibition of macrophage and endothelial cell nitric oxide synthase by diphenyleneiodonium and its analogs. FASEB J. 5, 98-103.

Tomi, N. S. and Luger, T. A. (2003) The treatment of atopic dermatitis with topical immunomodulators. Clin. Dermatol. 21, 215-224.

Wang, H. and Kochevar, I. E. (2005) Involvement of UVBinduced reactive oxygen species in TGF-beta biosynthesis and activation in keratinocytes. Free Radic Biol. Med. 38, 890-897. 